\title{
Original Article \\ Comparative Study of Temozolamide with Concurrent RT vs. Tamoxifen Plus Temozolamide, Concurrent RT in GBM Patients
}

\author{
Authors \\ Dr Niharika Panda ${ }^{1}$, Dr Samarendra Dash ${ }^{2}$, Dr Lucy Pattanayak ${ }^{3}$ \\ ${ }^{1}$ Associate Professor, Dept of Radiotherapy, Acharya Harihar Regional Cancer Centre, Cuttack, Odisha \\ ${ }^{3}$ Former PG Student, Department of Radiotherapy, Acharya Harihar Regional Cancer Centre, Cuttack, \\ Odisha, India, At present Consultant Apollo Cancer Hospital Ahmedabad \\ Email: samarendradas@gmail.com Mob: +919776895034 \\ ${ }^{3}$ Assistant Professor, Acharya Harihar Regional Cancer Centre, Cuttack, Odisha, India \\ Email: lucypattanayak2007@yahoo.co.in Tel: 91-9937028362 \\ Corresponding Author \\ Dr Niharika Panda \\ Associate Professor, Department of Radiotherapy \\ Plot No. N-3/462, IRC Village, Nayapalli, Bhubaneswar, Odisha, India 751015 \\ Email-niharika.panda@yahoo.com Mob: +919437487842
}

\begin{abstract}
Glioblastoma Multiforme (GBM) the most common primary tumour arising in the human brainrepresent a formidable clinical challenge. Despite advances which have been made in conventional surgical, radio therapeutic and chemotherapeutic modalities, the prognosis of such patients remains poor. The present prospective study is aimed at comparing the toxicity profile in GBM patients receiving high dose of Tamoxifen, Temozolamide and RT and secondly comparing the response of GBM patients. Patients with GBM at post operative stage having ECOG performance 0, 1, 2; life expectancy of $>8$ weeks who attended a regional cancer centre in South Eastern India were included in the study. A total of 30 patients were studied and were divided to two arms arm ' $A$ ' and arm ' $B$ '. External beam radiotherapy by cobalt 60 Theratron $780 \mathrm{C}$ was given at a dose of 60Gy in 30 fraction per week. Temozolamide was given in dose of $75 \mathrm{mg} / \mathrm{m}^{2}$ from day one to day 30 one hour before food and one hour before RT at the same time every day. Tamoxifen was given at dose of $40 \mathrm{mg} / \mathrm{m}^{2} /$ day from day 1 to day 30 before food in the morning hours. Toxicity was assessed using RTOG and common toxicity criteria. Both toxicity and response was evaluated during RT, six weeks after RT and subsequently at 3 months and 6 months of follow up. It was observed that high dose of Tamoxifen is well tolerated. Gastrointestinal and neurological toxicity were little higher and of grade 1 and 2. No retinopathy was observed. In Tamoxifen arm most patients showed partial response with stable disease.
\end{abstract} Keywords- Glioblastoma Multiforme (GBM), Tamoxifen, Temozolamide, RT.

\section{Introduction}

Glioblastoma Multiforme (GBM) the most common primary tumour arising in the human brain $^{1,2}$ represent a formidable clinical challenge. Despite advances which have been made in conventional surgical, radiotherapeutic and chemotherapeutic modalities the prognosis of such patients remains poor. The median survival of patients harbouring 
glioblastoma remains less than twelve months from the time of diagnosis. Previous work has demonstrated that the proliferation rates of malignant gliomas are sensitive to inhibitors of the PKC3 intracellular signal transduction system in-vitro. ${ }^{3-6}$ Malignant human gliomas express very high PKC activity when compared to non-transformed glial cells (2-3 orders of magnitude increase) and this high activity correlates strongly with the proliferation rates of these tumours in vitro. These observations have supported an important role of the PKC system in regulating glioma growth and have led to the speculation that PKC inhibitors may be utilized as adjuvants in the therapy of patients harbouring malignant gliomas. Tamoxifen inhibits PKC activity $^{3,7,8}$ and growth in some malignant glioma cell lines within the micromolar concentration range in vitro, a property distinct from its estrogen receptor blockade effect. Since the growth and PKC inhibitory response to Tamoxifen is dose dependent $^{3,9,10}$ the present clinical trial was undertaken to assess the clinical safety and possible efficacy of administering high dosage of Tamoxifen along with Temozolamide and RT to patients with malignant gliomas. Preliminary results with short follow up in a subset of the patients in this study have been reported in a brief communication. The aim of the present study is aimed at comparing the toxicity profile in GBM patients receiving high dose of Tamoxifen, Temozolamide and RT and secondly comparing the response of GBM patients.

\section{Materials \& Methods}

All patients with GBM post operation, post excision having ECOG performance 0, 1, 2, life expectancy of $>8$ weeks who attended a regional cancer centre in South Eastern India were included in the study. The study was prospective, interventional randomized and was conducted between November 2012 to November 2013. A total of 30 patients were studied and were divided to two arms arm ' $A$ ' and arm ' $B$ '. The inclusion criteria are histologically diagnosed supratentorial glioblastoma multiforme with in last five weeks, age more than 18 years, adult performance status, ECOG or life expectancy at least
8 weeks, haemoglobin not less than $10 \mathrm{gm} \%$, haematocrit at least $30 \%$, absolute neutrophil count of at least $1500 / \mathrm{cmm}$, platelet count of at least 1 lakh/cmm, liver function test values not greater than two times the normal, blood urea not more than $25 \mathrm{mg} / \mathrm{dl}$ and creatinine not more than $1.5 \mathrm{mg} / \mathrm{dl}$. The exclusion criteria taken were cases having recurrent malignant glioma, metastases below the tentorium or cranial vault, active thrombophlebitis, recovered from any post operative infection or other complications, major medical illness or psychiatric impairments that would preclude study participation, active connective tissue disorder such as lupus or scleroderma, other malignancy with in past five years except non melanomatous skin cancer or carcinoma in situ of the cervix or prior endometrial cancer or atypical endometrial hypoplasia. After obtaining the written consent and a check of eligibility cases, cases in arm A were given Temozolamide with concurrent RT and arm B Temozolamide with concurrent RT and Tamoxifen was given and were evaluated for response and toxicity. The evaluation was done by a careful history taking, clinical and neurological examination, biochemical tests, CECT or MRI imaging of brain preoperatively, surgical resection of tumour, TVS in female patients for endometrial hyperplasia, ophthalmoscopy and slit lamp examination for visual toxicity and USG Doppler was done to assess the deep vein thrombosis. The main stay of the study technique was radiation therapy by external beam radiotherapy by cobalt 60 Theratron $780 \mathrm{C}$. The dose and fractionation was $60 \mathrm{~Gy}$ in 30 fractions per week. Temozolamide was given in dose of $75 \mathrm{mg} / \mathrm{m}^{2}$ from day one to day 30 including week days, Saturday and Sunday. It was given one hour before food and one hour before RT at the same time every day. Tamoxifen was given at dose of $40 \mathrm{mg} / \mathrm{m}^{2} /$ day from day 1 to day 30 including week days, Saturday and Sunday before food in the morning hours. During treatment proper immobilisation device, face mask and appropriate head rest were used. The target volume was gross tumour (entire tumour as determined by the $\mathrm{T} 2$ weighted hyper-intense signal on MRI) with 2-3 cm margin. Most case were 
planned with two oblique wedge beams either as anterior/posterior or anterolateral. Some cases were planned with parallel opposed lateral fields.

The response was interpreted by cranial MRI performed just before the initiation of RT and again at 6 weeks after the end of RT to evaluate the objective tumour response using RECIST criteria. Toxicity was assessed using RTOG and common toxicity criteria. Both toxicity and response was evaluated during RT, six weeks after RT and the subsequently at 3 months and 6 months of follow up.

\section{Results}

A total number of 30 patients were available for study. The age distribution is given in Fig 1. It is observed that $40 \%$ of cases were in age group of 50 60 years with a median age of 56 years. $18(60 \%)$ cases were male and $12(40 \%)$ were female.

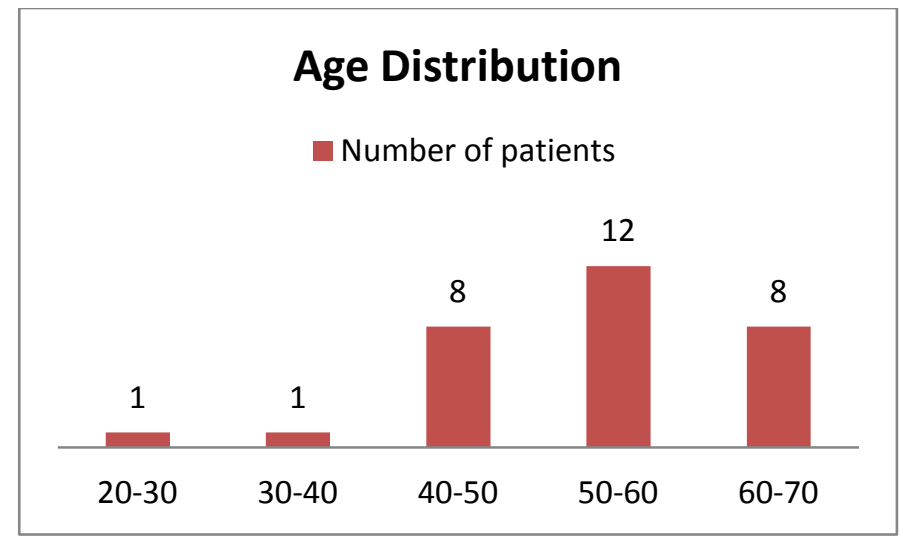

Fig. 1. Distribution of age in cases.

The extent of surgery and the ECOG status is shown in Table. No.1.

Table No 1 ECOG and surgery status of patients.

$\left.\begin{array}{|l|c|c|}\hline \text { S1 No } & \text { Parameters } & \begin{array}{c}\text { Number of cases } \\ (\%)\end{array} \\ \hline 1 & \text { ECOG status } & 08(26.67 \%) \\ & 0 & 12(40 \%) \\ & 1 & 10(33.33 \%)\end{array}\right)$

The different sites of GBM observed in both the arms are shown in Fig. 2.

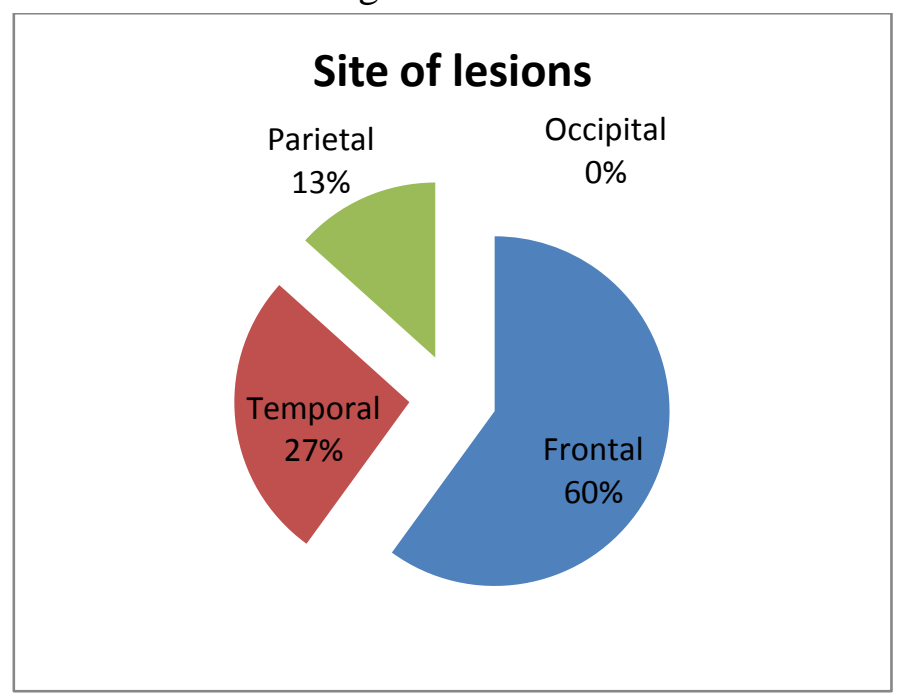

Fig. 2. Distribution of different sites of occurrence in cases.

The toxicity and response in the two arms are shown in Table No. 2 \& 3 respectively.

Table. No 2 Toxicity profile in two groups

\begin{tabular}{|c|c|c|}
\hline & $\begin{array}{c}\text { Arm A } \\
\text { (number of } \\
\text { patients \& \%) }\end{array}$ & $\begin{array}{c}\text { Arm B } \\
\text { (number of } \\
\text { patients \& \%) }\end{array}$ \\
\hline $\begin{array}{l}\text { Gastrointestinal } \\
\text { symptoms }\end{array}$ & $4(26.67 \%)$ & $7(46.67 \%)$ \\
\hline Nausea & 1 & 2 \\
\hline Vomiting & 1 & 2 \\
\hline Constipation & 1 & 1 \\
\hline Anorexia & 1 & 2 \\
\hline $\begin{array}{c}\text { Haematological } \\
\text { toxicity }\end{array}$ & $4(26.67 \%)$ & $4(26.67 \%)$ \\
\hline Leukopenia & 1 & 1 \\
\hline Thrombocytopenia & 1 & 1 \\
\hline Neutropenia & 1 & 1 \\
\hline Anaemia & 1 & 1 \\
\hline Neurological toxicity & $6(40 \%)$ & $8(53.33 \%)$ \\
\hline Headache & 2 & 2 \\
\hline Seizures & 1 & 2 \\
\hline Insomnia & 2 & 1 \\
\hline Neuropathy & 1 & 3 \\
\hline Other toxicities & 0 & 0 \\
\hline Visual & $8(53.33 \%)$ & $10(66.67 \%)$ \\
\hline Fatigue & 0 & $1(6.67 \%)$ \\
\hline Deep vein thrombosis & 0 & $8(53.33 \%)$ \\
\hline Hot flushes & $1(6.67 \%)$ & $2(13.33 \%)$ \\
\hline Hepatic & $12(80 \%)$ & $10(66.67 \%)$ \\
\hline Alopecia & & \\
\hline
\end{tabular}


Table. No 3 Response of patients during follow ups.

\begin{tabular}{|c|c|c|}
\hline & $\begin{array}{c}\text { Arm A } \\
\text { (number of } \\
\text { patients \& \%) }\end{array}$ & $\begin{array}{c}\text { Arm B } \\
\text { (number of } \\
\text { patients \& \%) }\end{array}$ \\
\hline Complete response & 0 & 0 \\
Partial response & $5(33.33 \%)$ & $6(40 \%)$ \\
Stable response & $7(46.67 \%)$ & $8(53.33 \%)$ \\
Progressive disease & 3 & $1(6.67 \%)$ \\
Follow up at 3 months & & \\
Surviving without & & \\
disease & 0 & 0 \\
Residual disease & $15(100 \%)$ & $15(100 \%)$ \\
Lost for follow up & 0 & 0 \\
Death & 0 & 0 \\
Follow up at 6 months & & \\
Surviving without & & $13(86.67 \%)$ \\
disease & 0 & $1(6.67 \%)$ \\
Residual disease & $12(80 \%)$ & $1(6.67 \%)$ \\
Lost for follow up & $1(6.67 \%)$ & \\
Death & $2(13.33 \%)$ & \\
& & \\
\hline
\end{tabular}

\section{Discussion}

Current results with all methodologies for the treatment of glioblastoma multiforme (GBM) continue to be disappointing. The use of surgical resection, radiation therapy, and chemotherapyproduces a median survival of less than one year (Robins et al., 2003) ${ }^{11}$. Chemotherapy has the potential to improve survival, but increase in survival have been marginal as on date (Robins et al., $2003)^{11}$. A series of studies have suggested that the proliferation of high- grade gliomas is in part dependent on the activation of Protein Kinase C (PKC) mediated pathways (Baltuch et al. 1995 ${ }^{12}$; Gelmann, $1997^{13}$;. Thus, blocking this enzyme, which is known to be involved in signal transduction, provides an ideal approach to inhibiting glioma cell growth. Beyond this, investigations have suggested that inhibition of PKC can enhance the ionizing effects of irradiation (Chmura et al.1997 ${ }^{14}$ ) Relevant to this, the anti-estrogen Tamoxifen is a significant PKC inhibitor as illustrated by (Baltuch et al., $1995^{12}$; Mastronardi et al. $1998 \mathrm{~b}^{15}$;).

At concentrations several fold higher than that used in its traditional role as an estrogen receptor- binding agent, Tamoxifen can nock glioma cell lines in vitro. By extrapolation, oral dosing in excess of $80 \mathrm{mg} / \mathrm{m}^{2}$ can achieve a serum concentration in a putative therapeutic range. In this regard, Couldwell et al. ${ }^{16}$ reported both safety and efficacy in a small series (i.e.; responses in 4 of $20 \mathrm{GBM}$ patients) at a dose of 160 to $200 \mathrm{mg}$ per day. The results of this study, as well as those of smaller series and anecdotal reports, are consistent with continued investigation of Tamoxifen in this patient population (Chang et al. ${ }^{17}$ Gelmann et al, ${ }^{13}$ Mastronardi et al., $1998 b,{ }^{15}$ Pollack et $\left.a l ., 1997^{18}\right)$. For more than three decades, postoperative radiotherapy has been the standard treatment for newly diagnosed glioblastoma. In 2004, the European Organisation for Research and Treatment of Cancer (EORTC) 26981-22981 National Cancer Institute of Canada Clinical Trials Group (NCIC) CE3 randomised phase III trial showed the addition of concomitant and adjuvant Temozolamide to standard postoperative radiotherapy, improved median survival and 2-year survival relative to postoperative radiotherapy alone. In our study we have evaluated the role of both high dose Tamoxifen and Temozolamide concurrent with RT. Total 30 patients were enrolled in the study out of which 15 patients were allocated to arm A and 15 patients in arm B. According to literature the GBM occurs frequently in the range of 45-70 yrs of age (Gabriel Lacob et $\mathrm{al}^{19}$ ), In our study most of the patients were in $5^{\text {th }}$ decade. Incidence of GBM is slightly higher in males than in females in $\mathrm{H}$ ratio of 60:40 (Gabriel Lacob ${ }^{19}$ ). In our study males were 60 and females were 40. ECOG of most of the patients was in range of 0-2 and none was above 2 . Out of 30 patients enrolled in the study 3(10\%) patients had undergone biopsy only, near complete resection was done only in $4(13.33 \%)$ patients and $23(76.67 \%)$ no of the patients had undergone partial resection. Most common location of tumour in our study was frontal lobe $(60 \%)$ followed by temporal (26.67\%) and parietal (13.33\%).

In previous studies like (Robins $\mathrm{HL}^{11}$ ) reported an incidence of $38 \%$ for nausea and vomiting which were mostly grade 1 and 2 . In our study the incidence was higher in arm B with an incidence of $13.33 \%$ ( 2 patients) as compared to arm $\mathrm{A}$ in which the incidence was $6.67 \%$ (1 patient). But in most of 
the cases nausea and vomiting was controlled by simple anti-emetics. The incidence of nausea and vomiting in our study was much less as compared to previous studies as the dose of Tamoxifen $\left(40 \mathrm{mg} / \mathrm{m}^{2}\right)$ in our study was much lower. Constipation was seen in one patient in arm A and one patient in arm B which was mainly functional. Haematological toxicity in both the arms were similar as Tamoxifen does not contribute to haematotoxicity. Grade 3 leukopenia and thrombocytopenia was observed in one patient in arm A and one patient in arm B. The incidence was $6.67 \%$ in both the arms which was similar to that of previous trials in which they reported an incidence of 3-15\%. Also the major toxicities reported by Alexander $\mathrm{M}$ et al with use of Tamoxifen with Temozolamide was grade 4 pancytopenia, but this trial used Temozolamide for a prolonged period and the dose of Tamoxifen was much higher.

The same patients also reported to have grade 2 neutropenia which was transient and the patients recovered with growth factors and antibiotics. Grade 1 anaemia was also observed in one patient in arm A and one patient in arm B which was managed with blood transfusion. Seizures was seen in two patients in $\operatorname{arm} \mathrm{B}$, and one patients in arm $\mathrm{A}$ but it was mostly due to primary disease rather than mode of treatment. Out of the 3 patients 2 had features of raised ICT (intracranial pressure). 3 patients had insomnia which was managed by benzodiazepines. Neuropathy was mainly sensory type due to cortical involvement however the overall neurological toxicity was disease related rather than treatment. Hepatotoxicity was seen in 2 patients $(13.33 \%)$ in arm B and only 1 patient $(6.67 \%)$ in arm A. But these were grade 1 toxicity. Alberto Broniscer $2000^{20}$, reported an incidence of $17 \%$ of hepatotoxicity which were mostly grade 2 . In our study the incidence was slightly less and mostly grade 1 and the dose of Tamoxifen used in the above study was much higher than compared to our study. Alberto Broniseer 2000 stated that although the most commonly found histologic abnormality is hepatic steatosis, in rare cases the medication causes clinically and histologically proven acute hepatitis or massive liver damage. But none of our cases reported grade 2 or 3 toxicity. According to Alexander M. $^{21}$, transaminitis grade III was seen in $12.5 \%$ of patients. Deep vein thrombosis was seen only in one patient in arm B (6.67\%). The study most comparable to this trial was reported by Muanza et al. $(2000)^{22}$. This was a pilot toxicity study of 12 GBM patients in which high-dose TAM was given with and after radiotherapy. There was one episode of deep vein thrombosis (DVT) reported in that trial. The incidence of thromboembolic problems reported by Robins et $\mathrm{al}^{11}$ for RT and Tamoxifen for GBM was (20.8\%). Alexander M.2004 reported an incidence of $12.5 \%$ for DVT which were grade 4 . The patient who had thrombosis was managed conservatively and continued treatment. Fifty-nine percent of the women aged $<50$ years experienced significant hot flushes with Tamoxifen. Day R $2001^{23}$ reported an incidence of $80 \%$ in women receiving Tamoxifen. In our study $8(53.33 \%)$ female patients complained of hot flushes in arm B which was similar to that of previously reported incidence.

Case reports and case series identify crystalline retinal deposits, macular oedema, and corneal changes as potential Tamoxifen ocular toxicities. Though Tamoxifen usually causes late ocular toxicity none of the patient showed any signs of visual toxicity probably as the dose in our study were much lower. Nayfield SG et $\mathrm{al}^{24}$ stated that Ocular toxicity is uncommon in the current clinical setup of long-term, low-dose Tamoxifen use. Grade 3 skin toxicity of focal alopecia was seen in 12 patients in arm $\mathrm{A}$ and in 10 patients in arm B. Grade 2 fatigue was seen in 8 patients $(53.33 \%)$ in arm $\mathrm{A}$ and 10 patients $(66.67 \%)$ in arm B. Alexander M $2004^{21}$ reported grade 3 fatigue in $6.25 \%$ of patients. In our study complete response was not seen in any of the patient but partial response was seen in 6(40\%) patients, stable disease was seen in $8(53.33 \%)$ patients, and 1 patient $(6.67 \%)$ showed progressive disease. Results of a Brazilian Cooperative Study by Alberto Broniscer published in JCO 2000 reported that in radiation therapy and high-dose Tamoxifen in the treatment of patients with diffuse brainstem 
gliomas $36 \%$ patients had partial response, $36 \%$ had stable disease and $14 \%$ had progressive disease. But this study did not include Temozolamide. In another study Phase II trial of thalidomide, Tamoxifen, and Temozolomide for patients with advanced malignant gliomas by Tamoxifen. Ahmed $\mathrm{T}$ et $\mathrm{al}^{25}$ published in JCO 2005, showed disease stabilization in $64 \%$ of patient and complete response was not seen. 1 patient remained progression free for 2 years but this study did not include RT. In another study by Alexander $M$ published in Journal of Neurooncology, 2004, a Phase II study of concurrent continuous Temozolomide and Tamoxifen for recurrent malignant astrocytic gliomas, out of sixteen enrolled patients there was one partial response and one stable disease. Eleven patients progressed by the end of cycle 1, three patients failed due to toxicity before completing cycle 1 . In another study by Rabbani G in $2007^{26}$ mentioned that the combination of Temozolamide, Thalidomide and Tamoxifen administered as outpatient oral therapy resulted in significantly improved quality of life for patients with malignant astrocytomas without significant toxicity.

In a study by Patel $\mathrm{S}$ et $\mathrm{al}^{27}$ the Tamoxifen in dose $100 \mathrm{mg} / \mathrm{m}^{2}$ when given concurrently with Temozolomide $75 \mathrm{mg} / \mathrm{m}^{2}$ and RT., Tamoxifen might have a role in the initial treatment of high-grade gliomas and should be studied in future Phase II trials on the newly established platform of concurrent chemo-radiotherapy. On follow up at 6 months after RT, no major complications were reported, At 6 months follow up 12 (80\%) of patients in arm A were surviving with disease compared to 13( $86.67 \%)$ of patients in arm B. Two patients $(13.33 \%)$ died in arm A and one patient (6.67\%) died in arm B. Progression of disease was higher in arm A as compared to arm B. We did not observe any evidence of myelo-suppression, cardiac arrhythmias, or retinopathies at 6 months follow up.

\section{Conclusion}

The present study highlighted the role of PKC inhibitors i.e. Tamoxifen in management of Glioblastoma Multiforme. The study indicates that
GBM patients respond to and are stable with high dose of Tamoxifen with Temozolamide and RT. The patients show a good tolerance. As the sample size in the present study is small further study can help in establishing the definitive role of high dose of Tamoxifen along with Temozolamide and RT.

\section{Acknowledgement}

We sincerely thank Dr. Surendra Nath Senapati, Professor, Radiotherapy, AHRCC Cuttack for his endless advise and guide.

No source of support or grant, declared.

No conflict of interest, declared.
Abbreviations
RT - Radiotherapy
GBM - Glioblastoma Multiforme
ECOG - Eastern Cooperative Oncology Group
RTOG - Radiation Therapy Oncology Group
PKC - Protein Kinase C 3
CECT - Contrast Enhanced Computed Tomography
MRI - Magnetic Resonance Imaging
USG - Ultrasonography
DVT - Deep Vein Thrombosis

RECIST - Response Evaluated Criteria In Solid Tumors

\section{References}

1. Leibel SA, Scot CD, Loeffler JS. Conrtemporary approaches to the treatment of malignant gliomas with radiation therapy. Sem Oncol 1994; 21:198-219

2. Devita VT, Hellman S, Rosenberg SA. Cancer principles and practice of oncology. $5^{\text {th }}$ Edition, Lippincort Raven; 1997;2023

3. Baltuch G, Couldwell WT, et al. Protein kinase $\mathrm{C}$ inhibitors suppress cell growth in established and low passage from glial cell lines. A comparison between staurosporine and Tamoxifen. Neurosurgery. 1993;33:495501

4. Couldwell WT, Antel JP,et al. Enhanced protein kinase $\mathrm{C}$ activity correlates with the growth rate of malignant gliomas. Part II. 
Effects of glioma mitogens and modulators of PKC. Neurosurgery. 1992;31:714-724

5. Couldwell WT, Uhm $\mathrm{J}$ et al. Enhanced protein kinase in $\mathrm{C}$ activity correlates with the growth rate of malignant human gliomas. Neurosurgery. 1991;29:880-887

6. Nishizuka Y. Intracellular signalling by hydrolysis of phospholipids and activation of protein kinase C. Science (Washington DC) 1992; 252:607-614

7. O'Brian CA, Liskamp RM et al. Inhibition of protein kinase $\mathrm{C}$ by Tamoxifen. Cancer Res.1985;45:2462-2465

8. Pollack IF, Randall MS et al. Effect of Tamoxifen on DNA synthesis and proliferation of human malignant glioma lines in vitro. Cancer Res. 1990;50:71347138

9. Vertosik FT, Selker RG et al. The treatment of intracranial gliomas using orally administered Tamoxifen therapy. Preliminary results in a series of failed patients. Neurosurgery. 1992;30:897-903

10. Couldwell WT, Hinton DR et al. Protein Kinase $\mathrm{C}$ inhibitors induce apoptosis in human malignant glioma lines. FEBS Letters. 1994;345:43-46

11. Robins HI, Peterson CG, Mehta MP. Combined modality treatment for central nervous system malignancies. Semin Oncol. 2003;30 (suppl. 9):11-22.

12. Baltuch GH, Dooley NP, Villemure JG, Yong VW. Protein kinase $\mathrm{C}$ and growth regulation of malignant gliomas. Can J Neurol Sci. 1995;22:264-271

13. Gelmann EP. Tamoxifen for the treatment of malignancies other than breast and endometrial carcinoma. Semin Oncol. 1997; 24(suppl.):S1-65-S1-70.

14. Chmura SJ, Mauceri HJ, Advani S, Heimann R, Beckett MA, Nodzenski E, Quintans J, Kufe DW, Weichselbaum RR. Decreasing the apoptotic threshold of tumor cells through protein kinase $\mathrm{C}$ inhibition and sphingomyelinase activation increases tumour killing by ionizing radiation. Cancer Res. 1997;57:4340-4347

15. Mastronardi L, Puzzilli F, Couldwell WT, Farah JO, Lunardi P. Tamoxifen and carboplatin combinational treatment of highgrade gliomas: Results of a clinical trial on newly diagnosed patients. J Neuro Oncol. 1998b;38:59-68

16. Couldwell WT, Hinton DR, Surnock AA, DeGiorgio CM, Weiner LP, Apuzzo ML, Masri L, Law RE, Weiss MH. Treatment of recurrent malignant gliomas with chronic oral high-dose Tamoxifen. Clin Cancer Res. 1996;2:619-622

17. Chang SM, Barker FG, II, Huhn SL, Nicholas MK, Page M, Rabbitt J, Prados MD. High dose oral Tamoxifen and subcutaneous interferon alpha-2a for recurrent glioma. J Neurooncol. 1998;37:169-176.

18. Pollack IF, DaRosso RC, Robertson PL, Jakacki RL, Mirro JR, Jr, Blatt J, Nicholson $\mathrm{S}$, Packer RJ, Allen JC, Cisneros A, Jordan VC. A phase I study of high-dose Tamoxifen for the treatment of refractory malignant gliomas of childhood. Clin Cancer Res. 1997;3:1109-1115.

19. Gabriel Lacob et al. Current data and strategy in glioblastoma multiforme. Journal of Medicine and Life 2009; 2 (4) 386-393

20. Alberto Broniscer et al. Radiation Therapy and High-Dose Tamoxifen in the Treatment of Patients With Diffuse Brainstem Gliomas. Results of a Brazilian Cooperative Study. J Clin Oncol;2000:18(6):1246-1253

21. Alexander $M$ et al. Phase II Study of Concurrent Continuous Temozolomide (TMZ) and Tamoxifen (TMX) for Recurrent Malignant Astrocytic Gliomas. J Neuro Oncology.2004;70(1):91-95

22. Muanza T, Shenouda G, Souhami L, Leblanc R, Mohr G, Corns R, Langleben A. High dose Tamoxifen and radiotherapy in patients with glioblastoma multiforme: A phase IB study. Can J Neurol Sci. 2000;27:302-306. 
23. Day R, Ganz PA, Costantino JP, Cronin WM, Wickerham DL, Fisher B. Health-related quality of life and Tamoxifen in breast cancer prevention: a report from the National Surgical Adjuvant Breast and Bowel Project P-1 Study. J Clin Oncol 1999;17:2659-69.

24. Nayfield SG et al. Tamoxifen-associated eye disease, a review. J Clini Oncol. 1996; 14(3):1018-1026.

25. Ahemed T et al. Phase II trial of thalidomide (TD), Tamoxifen (TX), and Temozolomide (T) for patients with advanced malignant gliomas (MG). Journal of Clinical Oncology 2005; 23(16):1575-1575.

26. Rabbani $G$ et al. Combination therapy with thalidomide, Temozolomide and Tamoxifen improves quality of life in patients with malignant astrocytomas. Anticancer Res. 2007; 27(4C):2729-36

27. Patel $\mathrm{S}$ et al. Phase I clinical trial assessing Temozolamide and Tamoxifen with concomitant radiotherapy for treatment of high-grade glioma. Int J Radiat Oncol Biol Phys. 2012; 82(2):739-42. 